\title{
Are ICFs suitable building envelope solutions for Mediterranean climatic conditions? A critical analysis concerning thermal properties and cooling energy performances
}

\author{
Cristina Carpino, Roberto Bruno, Piero Bevilacqua, Natale Arcuri
}

\author{
Department of Mechanical, Energy and Management Engineering (DIMEG), University of \\ Calabria, P. Bucci 46/C, 87036, Rende (CS), Italy \\ e-mail: cristina.carpino@unical.it
}

\begin{abstract}
The ICF (Insulated Concrete Forms) constructions, consisting of insulating permanent formworks filled with cast-in-place reinforced concrete, are widely used in Continental climates. The present work addresses the adaptation of ICF systems to the Mediterranean climate, by evaluating through dynamic simulation the effect of certain adjustments in wall layering aimed at making more exploitable the internal thermal mass. The results show that the replacement of the internal insulating form with alternative materials, characterized by a higher thermal conductivity, allows to lower internal air temperature peaks up to $1.4{ }^{\circ} \mathrm{C}$ compared to standard ICFs, and reduce cooling energy consumption by $20 \%$. The alternative solutions are also effective in terms of costs and construction time. Modified ICF solutions can be profitably used for zero energy buildings even in warm climates.
\end{abstract}

\section{Introduction}

Latest Standards introduced nearly Zero Energy Buildings (nZEBs) that require a minimum amount of fossil energy for their operation (Directive 2010/31/EU). The high efficiency is based primarily on the minimisation of energy requirements for air conditioning. Generally, the reduction of the heating demand is easily achievable, through an adequate envelope insulation and a profitable exploitation of solar gains. On the contrary, in climatic conditions in which the cooling demand prevails, the containment of energy consumption becomes more challenging. However, experiences of low-energy buildings in different climatic contexts can be found in the literature. For example, (Schnieders et al., 2015) analysed the possibility of realising Passive Houses in all the world's relevant climate zones by adjusting building's shape and orientation, insulation level, window quality and mechanical services in each individual case, maintaining architectural quality and internal comfort. (Harkouss et al., 2018) proposed best practices to reduce building energy demand for cooling and heating by improving the passive design. Twenty-five different climates were simulated in the study showing that an optimal passive solution can produce a potential saving up to $54 \%$ for cooling demand and up to $87 \%$ for heating demand, with respect to the initial configuration. Basic principles for the design of nZEBs in Mediterranean climate are provided by (Ascione et al., 2016a). (Ascione et al., 2016b) sought to identify integrated design procedures able to minimise both winter and summer energy demand of a residential case study in four Mediterranean cities (Madrid, Nice, Naples, Athens) and evidenced the difficulty of assuring high thermal comfort when looking for the nZEB objective. A parametric analysis aimed at the optimisation of the envelope of a passive building in South Italy is shown in (Bruno et al., 2015) proving that a proper layering of the external elements can decrease cooling requirements. The design and monitoring of a high-performance home in Mediterranean climate are reported in (Causone et al., 2017) by highlighting the key role played by the control of heat gains and the correct use of the thermal mass. The role of thermal storage capacity as a passive strategy to maintain internal comfort is also emphasised by (Rodriguez-Ubinas et al., 2014). As discussed in (Lizana et al., 2017) thermal energy storage is essential to accomplish the low-carbon energy goal in the building sector, allowing to reduce energy consumption and promote the use of renewable energy sources.

(Fadejev et al., 2017) demonstrated how interior thermal mass of enough thick concrete layers can enable utilisation of solar and internal gains resulting in a significant reduction of peak loads both for heating and cooling and in a reduction of total energy need. (Al-Sanea et al., 2012) investigated the effect of amount and location of thermal mass in insulated building walls with the same nominal resistance, on total and peak transmission loads, time lag, decrement factor, and dynamic resistance. They found out that, a maximum saving in yearly transmission loads of about $17 \%$ for cooling and $35 \%$ for heating is achievable with the optimisation of the thermal mass and that, for a given thermal mass, external insulation gives better overall thermal performance than internal insulation. (Siddiqui et al., 2017) found that the use of thermal mass in Net-Zero Energy houses contributes for $10-15 \%$ to energy savings and considerably contributes to the comfort of the occupants. The influence of the thermal storage mass on summer thermal stability of a passive house in the Czech Republic is described by (Němeček and Kalousek, 2015), by analysing different construction variants including wooden and brick-built envelopes. The sensible heat stored in the building materials was considered and a curve illustrating the effectiveness of thermal mass in preventing overheating was drawn. Experimental and theoretical analysis of the 
energy performance of lightweight and massive wall systems is presented by (Kosny et al., 2001.). Dynamic thermal performance of 16 alternatives for the wall stratigraphy was investigated for residential buildings and the potential energy savings were presented for ten U.S. climates proving that thermal mass can help in the reduction of building annual energy use. Therefore, massive building envelopes can be utilised as one of the simplest ways of reducing building heating and cooling loads. As widely known, constructions made in masonry or earth are able to provide the structure with a high thermal inertia. Furthermore, concrete has also been demonstrated to have suitable thermal storage capacity (Shafigh et al., 2018) and solutions based on Insulated Concrete Forms (ICFs) can represent a valid alternative to traditional construction methods. ICFs structures consist of cast-in-place concrete walls that are sandwiched between two layers of insulation material. This building system offers numerous advantages. It provides continuous insulation without thermal bridging, acoustic insulation, air sealing, waterproofing, high structural strength and seismic safety. Moreover, it allows fast and easy construction and high flexibility. Several studies focused on mechanical and structural properties of ICFs (E.Arunraj; Arun Solomon; G Hemalatha, 2014) (Arun Solomon and Hemalatha, 2017) (Bhatti, 2016) (AmerYahia and Majidzadeh, 2012) while few works investigated its thermal characteristics and energy behaviour. The thermal response of ICF assembly subjected to different Canadian climate conditions was analysed by Maref et al., 2012. Ekrami et al., 2015a investigated thermal behaviour of the concrete in ICF walls embedding PVC pipes in order to store thermal energy and make it available when there is a demand, in particular reusing it as an input of other mechanical systems such as heat pumps. (Ekrami et al., 2015b) used a test facility to evaluate the application of Insulated Concrete Forms walls combined with Ventilated concrete Slabs in order to experimentally verify the effect of thermal energy storage systems on the overall performance of a coupled photovoltaic/thermal and air source heat pump. ICF technique has been widely used in cold climates thanks to its ability to control heat losses and meet higher energy code mandates with less complicated construction. However, its application in warm/hot climates is still relatively unexplored. An example in this direction is given by the study carried out by (Selvapandian A., 2014), which examined the feasibility of using ICFs in a hot and humid climate. Hygro-thermal performances of ICF walls and traditional concrete walls for a building in Oman were studied with reference to the peak summer months and the results indicated the ICFs are comparatively better than normal concrete block walls.

The present paper deals with the use of ICF structures in Mediterranean climate for obtaining nearly zero energy buildings. Steady and dynamic thermal properties are determined by considering different wall layering and the overall energy performance of a building is evaluated. In particular, solutions based on the replacement of the internal insulation layer of the formwork with material characterized by higher thermal conductivity are examined, in order to make the activation of the thermal mass involved in the wall more effective. Finally, an economic analysis is performed in order to identify the most cost-effective solution, being able to reduce construction time and operating costs.

\section{Data and methodology}

The methodology can be divided into the following phases:

- Presentation of the case study and simulation hypotheses

- Detailed description of the analysed stratigraphies for external walls and calculation of the steady and dynamic thermal characteristics

- Analysis of the results in terms of trend in indoor air temperature and energy requirements for cooling

- Economic projections for the identification of the most cost-effective solution.

\section{Case study and simulation assumptions}

A single-family house was considered for the analysis. The layout of the designed building is shown in figure 1 . The net surface is of $118.7 \mathrm{~m}^{2}$. The window to wall ratio is equal to $27 \%$ for the South exposure, and equal to $16 \%$ and $30 \%$ for the North and East exposures, respectively. A horizontal overhang of $1.5 \mathrm{~m}$ is provided on the windows facing South. The windows are double-paned (4-12-4 $\mathrm{mm}$ with air) with wooden frames $\left(\mathrm{Uw}=1.9 \mathrm{~W} / \mathrm{m}^{2} \mathrm{~K}\right)$.

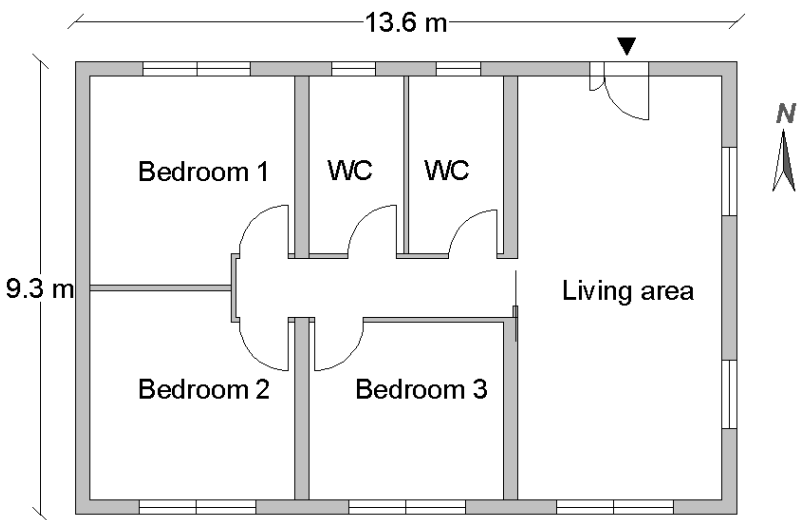

Figure 1. Layout of the single-family house assumed for energy performance assessment.

Internal gains are calculated according to the Standard (UNI/TS 11300-1, 2014) and are equal to $3.80 \mathrm{~W} / \mathrm{m}^{2}$. A natural ventilation rate of 0,3 ach is assumed according to the standard (UNI/TS 11300-1, 2014). Regarding climatic conditions, a weather file generated with Meteonorm (Meteonorm, 2017) for a city located in southern Italy (Cosenza) is used in the analysis. The maximum external air temperature is $36.4{ }^{\circ} \mathrm{C}$, the maximum value of the direct normal solar radiation is $0.997 \mathrm{~kW} / \mathrm{m}^{2}$ while the maximum value of the diffuse solar radiation on a horizontal surface is $0.489 \mathrm{~kW} / \mathrm{m}^{2}$. 
Cooling Degree Day are equal to 148 , referring to a temperature of $26^{\circ} \mathrm{C}$ (UNI 10349-3, 2016). The building is equipped with a chilled ceiling connected to an airwater heat pump (EER 5.5) supplied by electricity from the grid.

The study focused on the evaluation of the building energy performance during the cooling season. For this purpose, energy simulations were conducted for six months, from $1^{\text {st }}$ May to $31^{\text {st }}$ October, using the DesignBuilder software (DesignBuilder Software Ltd, 2016) based on the EnergyPlus engine (EnergyPlus, 2015).

The cooling set-point temperature was set to $26^{\circ} \mathrm{C}$ with activation of the cooling system for ten hours a day, from 12:00 to 22:00. This operation schedule allows highlighting the effect of the thermal inertia of the building envelope. Simulation results are reported in terms of internal air temperature trends and electric energy for cooling.

\section{Description of the types of layering analysed for external walls}

The building is in load-bearing walls. Several types of external walls were analysed in the present study. All the considered solutions include thermal insulation in order to verify the limit values of thermal transmittance suggested by the current Italian regulations (D. M. 26 June, 2015) in function of the climatic zone. In particular, the location selected for the design of the building is within the climatic zone C (D.P.R. 412, 1993) and a value of $\mathrm{U}=0.34 \mathrm{~W} / \mathrm{m}^{2} \mathrm{~K}$ is prescribed for the refurbishment of existing building envelopes. Three construction solutions were considered, as illustrated in figure 2 , generating a set of seven technical alternatives in total. The thermophysical properties of all the materials used in the analysed types of wall are listed in Table 1 . Table 2 shows the detailed stratigraphy of all the seven technical alternatives, while Table 3 display the steady and dynamic thermal characteristics of the various component examined. The first wall type, named as Brick, is traditional brick masonry with ETICS (External Thermal Insulation Composite System). The second wall type, identified as Reference ICF (Ref ICF) consists of a standard ICF system. This type of construction, corresponding to the ICF system currently available on the market, uses permanent formworks consisting of insulation material, containing the concrete cast. The thickness of the insulating formworks can vary according to the specific needs. For the examined location, two EPS formworks with a thickness of $5 \mathrm{~cm}$ are satisfactory. However, this technology presents a limit due to the insulation layer located on the inner side that prevents full exploitation of the thermal mass included in the wall. For this reason, the third type of wall was introduced, assuming the replacement of the internal formwork, usually made of EPS or other insulating material, with alternative materials characterized by a higher thermal transmittance, in order to take greater advantage of the thermal mass inside the wall.

In particular, five substitute materials were examined, selected among those commercially available: cellular concrete panel, wood-cement board, gypsum fibre panel, plasterboard, and glass fibre reinforced lightweight concrete board. These are indicated with the codes ranging from ICF mod_l to ICF mod_5. All the considered materials can fulfil the formwork function, as an alternative to the EPS layer provided in the reference ICF wall and all these materials have a higher thermal conductivity than the EPS panel.

Since the analysis was conducted assuming a constant thermal transmittance $\mathrm{U}$, in the alternative ICF walls in which the internal formwork is replaced with a more conductive material, the thickness of the outer insulating layer is increased in order to reach the same thermal transmittance value for all the studied cases.

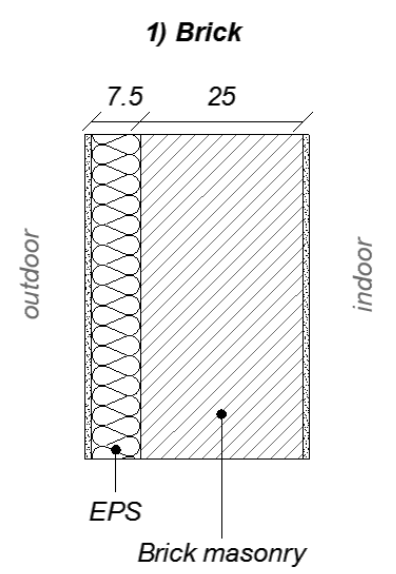

$\underline{\text { Traditional brick masonry }}$ with ETICS

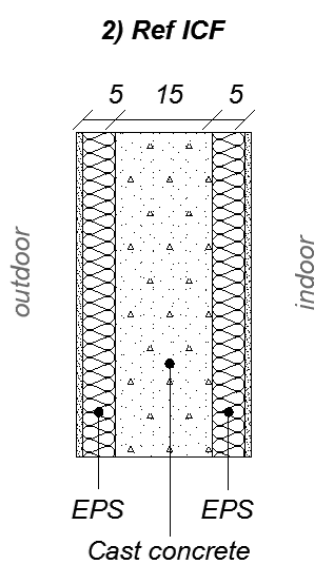

Standard ICF wall

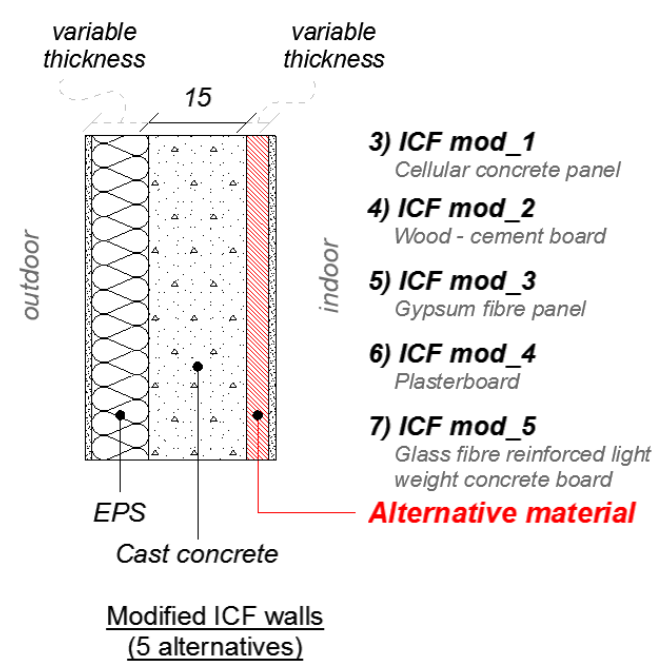

Figure 2. Technical solutions analysed for external walls. 
Table 1. Thermo-physical properties of the materials used in the wall layering. $\lambda$ : Thermal conductivity

$[\mathrm{W} / \mathrm{mK}], \rho:$ density $\left[\mathrm{kg} / \mathrm{m}^{3}\right], c_{p}$ : specific heat $[\mathrm{J} / \mathrm{kgK}]$.

\begin{tabular}{|l|c|c|c|}
\hline & $\lambda[\mathbf{W} / \mathbf{m K}]$ & $\boldsymbol{\rho}\left[\mathbf{k g} / \mathbf{m}^{\mathbf{3}}\right]$ & $\mathbf{c}_{\mathbf{p}}[\mathbf{J} / \mathbf{k g K}]$ \\
\hline Plaster & 0.400 & 1000 & 1000 \\
\hline Brick masonry & 0.313 & 796 & 837 \\
\hline Cast concrete & 2.300 & 2300 & 1000 \\
\hline EPS (Expanded Polystyrene) & 0.034 & 25 & 1255 \\
\hline Cellular concrete panel & 0.152 & 550 & 1050 \\
\hline Wood-cement board & 0.101 & 550 & 1506 \\
\hline Gypsum fibre panel & 0.320 & 1150 & 1100 \\
\hline Plasterboard & 0.210 & 900 & 837 \\
\hline $\begin{array}{l}\text { Glass fibre reinforced light } \\
\text { weight concrete board }\end{array}$ & 0.173 & 1000 & 1000 \\
\hline
\end{tabular}

\section{Results and discussion}

\section{Energy performance}

The exploitation of the thermal inertia of the envelope allows for the reduction of the internal air temperature peaks and, consequently, the required maximum cooling power. Figure 3 shows the results obtained for freefloating simulations. The indoor air temperature trends are reported together with the outdoor air temperature and the direct normal solar radiation.

As can be seen from the graph, all the five alternative ICF wall solutions have a very similar temperature trend. This shows that, once the thermal insulation layer on the inner side (EPS, $\lambda=0.034 \mathrm{~W} / \mathrm{mK}$ ) has been removed, the use of one of the substitute materials considered for the internal formwork $(0.101 \mathrm{~W} / \mathrm{mK}<\lambda<0.210 \mathrm{~W} / \mathrm{mK})$ leads to analogous results.

Table 2. Detailed stratigraphy of the seven technical solutions investigated for external walls.

\begin{tabular}{|c|c|c|c|c|c|c|c|}
\hline \multicolumn{7}{|c|}{ Traditional brick masonry wall with ETICS } \\
\hline Code & Plaster [m] & \multicolumn{2}{|c|}{ EPS [m] } & Brick masonry [m] & Plaster [m] & Thickness [m] \\
\hline Brick & 0.010 & \multicolumn{2}{|c|}{0.075} & 0.250 & 0.010 & 0.3450 \\
\hline \multicolumn{7}{|c|}{ Reference ICF wall } \\
\hline Code & Plaster [m] & $\begin{array}{c}\text { Outer formwork } \\
\text { (EPS) [m] }\end{array}$ & $\begin{array}{c}\text { Cast concrete } \\
{[\mathbf{m}]}\end{array}$ & $\begin{array}{c}\text { Inner formwork (EPS) } \\
{[\mathbf{m}]}\end{array}$ & Plaster [m] & Thickness [m] \\
\hline Ref ICF & 0.010 & 0.05 & 0.150 & 0.050 & 0.010 & 0.2700 \\
\hline \multicolumn{7}{|c|}{} & \multicolumn{7}{|c|}{$\begin{array}{c}\text { Alternative ICF walls } \\
\text { Code }\end{array}$} & Plaster [m] & $\begin{array}{c}\text { Outer formwork } \\
\text { (EPS) [m] }\end{array}$ & $\begin{array}{c}\text { Cast concrete } \\
{[\mathbf{m}]}\end{array}$ & $\begin{array}{c}\text { Inner formwork (alternative } \\
\text { materials) [m] }\end{array}$ & Plaster [m] & Thickness [m] \\
\hline ICF mod_1 & 0.010 & 0.0888 & 0.150 & Cellular concrete panel & 0.050 & 0.010 & 0.3088 \\
\hline ICF mod_2 & 0.010 & 0.0882 & 0.150 & Wood-cement board & 0.035 & 0.010 & 0.2932 \\
\hline ICF mod_3 & 0.010 & 0.0981 & 0.150 & Gypsum fibre panel & 0.018 & 0.010 & 0.2861 \\
\hline ICF mod_4 & 0.010 & 0.0971 & 0.150 & Plasterboard & 0.018 & 0.010 & 0.2851 \\
\hline ICF mod_5 & 0.010 & 0.0975 & 0.150 & $\begin{array}{l}\text { Glass fibre reinforced light } \\
\text { weight concrete board }\end{array}$ & 0.0125 & 0.010 & 0.2800 \\
\hline
\end{tabular}

Table 3. Steady and dynamic characteristics of the different walls. $U$ : thermal transmittance $\left[\mathrm{W} / \mathrm{m}^{2} \mathrm{~K}\right]$, $Y_{i e}$ : periodic thermal transmittance $\left[\mathrm{W} / \mathrm{m}^{2} \mathrm{~K}\right]$, $\kappa_{i}$ : internal areal heat capacity $\left[\mathrm{kJ} / \mathrm{m}^{2} \mathrm{~K}\right]$, $f_{a}$ : attenuation factor [-], $\Phi$ : time shift [h].

\begin{tabular}{|c|c|c|c|c|c|}
\hline Wall type & $\begin{array}{c}\mathbf{U} \\
{\left[\mathbf{W} / \mathbf{m}^{2} \mathbf{K}\right]}\end{array}$ & $\begin{array}{c}\mathbf{Y}_{\mathbf{i e}} \\
{\left[\mathbf{W} / \mathbf{m}^{2} \mathbf{K}\right]}\end{array}$ & $\begin{array}{c}\mathbf{K}_{\mathbf{i}} \\
{\left[\mathbf{k J} / \mathbf{m}^{2} \mathbf{K}\right]}\end{array}$ & $\mathbf{f}_{\mathbf{a}}[-]$ & $\phi[\mathbf{h}]$ \\
\hline Brick & 0.310 & 0.058 & 41.46 & 0.188 & 10h $1^{\prime}$ \\
\hline Ref ICF & 0.310 & 0.015 & 13.07 & 0.048 & $7 \mathrm{~h} 40^{\prime}$ \\
\hline ICF mod_l & 0.310 & 0.027 & 32.72 & 0.087 & $8 \mathrm{~h} \mathrm{19'}$ \\
\hline ICF mod_2 & 0.310 & 0.026 & 31.93 & 0.084 & $8 \mathrm{~h} \mathrm{21'}$ \\
\hline ICF mod_3 & 0.310 & 0.053 & 62.57 & 0.171 & $7 \mathrm{~h} 22^{\prime}$ \\
\hline ICF mod_4 & 0.310 & 0.048 & 55.38 & 0.156 & 7h 23' \\
\hline$I C F$ mod_5 & 0.310 & 0.051 & 58.09 & 0.164 & 7h 19' \\
\hline
\end{tabular}

Table 4 details the temperature reductions that can be achieved by using the alternative materials for the internal formwork with respect to the Ref ICF wall.
The most suitable solution seems to be represented by the gypsum fibre panel. The use of this material on the inner side of the wall in place of EPS, in fact, allows a reduction of the temperature peaks of nearly $1{ }^{\circ} \mathrm{C}$. Therefore, in the following graphs only this solution will be reported, defined as ICF mod_3, in order to avoid overlapping of temperature trends and to have clearer and more readable graphs. Moreover, since alternative materials offer comparable energy performances, the choice will then be oriented by economic effectiveness, addressed later in the paper.

Table 4. Decrement of internal air temperature peaks $\left[{ }^{\circ} \mathrm{C}\right]$ achievable using the modified ICF solutions compared to the Ref ICF solution (free-floating simulation).

\begin{tabular}{|c|c|c|c|c|}
\hline $\begin{array}{c}\text { ICF } \\
\text { mod_1 }\end{array}$ & $\begin{array}{c}\text { ICF } \\
\text { mod_2 }\end{array}$ & $\begin{array}{c}\text { ICF } \\
\text { mod_3 }\end{array}$ & $\begin{array}{c}\text { ICF } \\
\text { mod_4 }\end{array}$ & $\begin{array}{c}\text { ICF } \\
\text { mod_5 }\end{array}$ \\
\hline $0.70^{\circ} \mathrm{C}$ & $0.67{ }^{\circ} \mathrm{C}$ & $0.95{ }^{\circ} \mathrm{C}$ & $0.88^{\circ} \mathrm{C}$ & $0.89^{\circ} \mathrm{C}$ \\
\hline
\end{tabular}


Temperature profiles for the three construction typologies (Brick, Ref ICF, and ICF mod_3), when the cooling system is operating, are compared in figure 4 .

In the time interval in which the cooling system is active, the air temperature reaches the fixed set-point value. Focusing on the hours in which the cooling plant is switched off, a higher and faster increase of indoor air temperature is registered for the Ref ICF wall compared to the traditional brick wall and modified ICF wall, proving that the internal thermal mass of the Ref ICF wall is not adequately exploited. On the contrary, the modified ICF wall exhibits a higher thermal inertia with respect to the other two solutions and it makes possible a reduction of the maximum temperature peak up to $0.5^{\circ} \mathrm{C}$ compared to the Brick wall and up to $1.4^{\circ} \mathrm{C}$ with respect to the Ref ICF wall. Table 5 indicates the decrease in air temperature that can be attained using the modified ICF solutions in place of the Ref ICF wall.

Table 5. Decrement of internal air temperature peaks $\left[{ }^{\circ} \mathrm{C}\right]$ achievable using the modified ICF solutions compared to the Ref ICF solution (simulation with HVAC).

\begin{tabular}{|c|c|c|c|c|}
\hline $\begin{array}{c}\text { ICF } \\
\text { mod_1 }\end{array}$ & $\begin{array}{c}\text { ICF } \\
\text { mod_2 }\end{array}$ & $\begin{array}{c}\text { ICF } \\
\text { mod_3 }\end{array}$ & $\begin{array}{c}\text { ICF } \\
\text { mod_4 }\end{array}$ & $\begin{array}{c}\text { ICF } \\
\text { mod_5 }\end{array}$ \\
\hline $0.80^{\circ} \mathrm{C}$ & $0.78{ }^{\circ} \mathrm{C}$ & $1.39^{\circ} \mathrm{C}$ & $1.26^{\circ} \mathrm{C}$ & $1.31^{\circ} \mathrm{C}$ \\
\hline
\end{tabular}

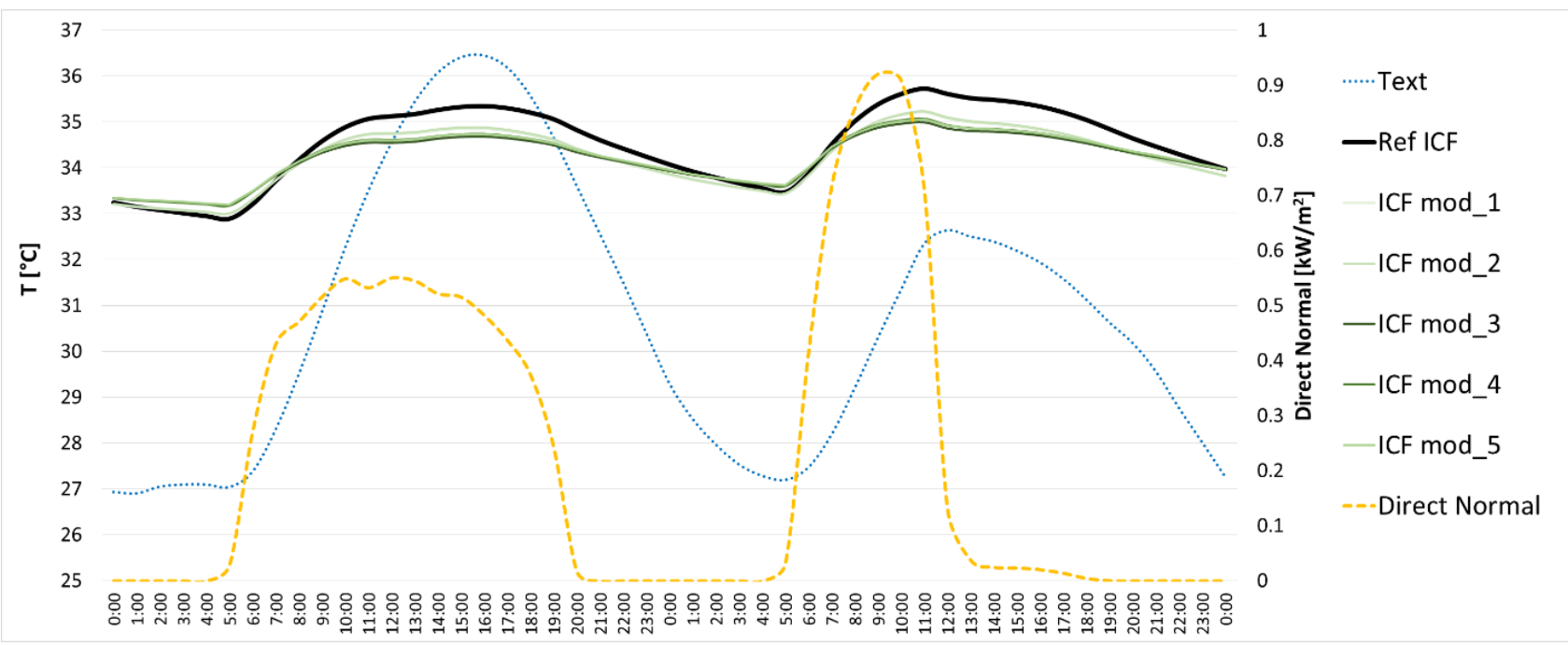

Figure 3. Comparison between the internal air temperature obtained using the Reference ICF wall and the five ICF alternative walls for two days, $21^{\text {st }}$ and $22^{\text {nd }}$ July - (Free-floating simulation).

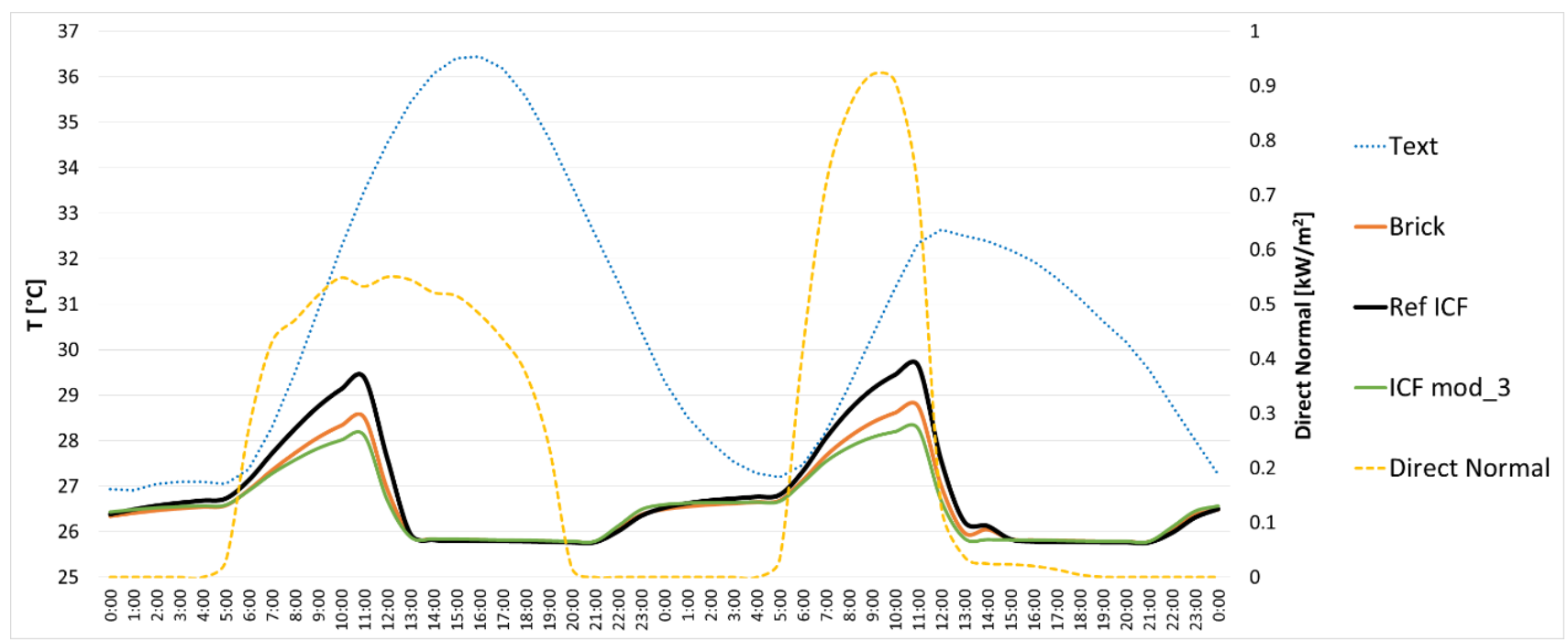

Figure 4. Comparison between the internal air temperature obtained using Reference ICF, Brick, and ICF mod_3 walls, for two days, $21^{\text {st }}$ and $22^{\text {nd }}$ July - (Simulation with HVAC). 
Figure 5 displays the cooling primary energy for the entire simulated period and for the seven constructive alternatives analysed.

As expected, the standard ICF solution involves a greater amount of energy for cooling compared to the traditional brick wall. Instead, the alternative ICF solutions allow to guarantee similar performances of the traditional masonry wall and in some case even better. This is a very interesting outcome because, in addition to the advantages obtained in terms of energy, it possible to benefit from all the advantages of ICF technology compared to traditional masonry (executive speed, ease of installation, flexibility, seismic safety, etc.). The percentage reductions in cooling primary energy for alternative ICF solutions with respect to the Ref ICF wall are summarized in table 6.

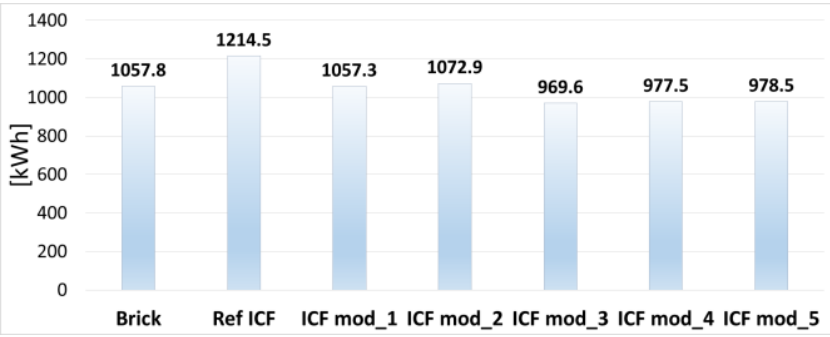

Figure 5. Cooling primary energy for the complete simulated period (from $1^{\text {st }}$ May to $31^{\text {st }}$ October) for all external wall types.

Table 6. Percentage reduction in cooling primary energy for alternative ICF solutions compared to the reference ICF wall.

\begin{tabular}{|c|c|c|c|c|}
\hline $\begin{array}{c}\text { ICF } \\
\text { mod_1 }\end{array}$ & $\begin{array}{c}\text { ICF } \\
\text { mod_2 }\end{array}$ & $\begin{array}{c}\text { ICF } \\
\text { mod_3 }\end{array}$ & $\begin{array}{c}\text { ICF } \\
\text { mod_4 }\end{array}$ & $\begin{array}{c}\text { ICF } \\
\text { mod_5 }\end{array}$ \\
\hline $12.9 \%$ & $11.7 \%$ & $20.2 \%$ & $19.5 \%$ & $19.4 \%$ \\
\hline
\end{tabular}

Regarding ventilation strategies, separate simulations were performed in order to explore the effect of introducing a nightly free cooling from 23:00 to 7:00, when the outdoor temperature decreases allowing to remove thermal energy stored in the building structure during the day. From this analysis, it turned out that nighttime ventilation decreases the difference in temperature between the various solutions and tends to equalize the energy needs. Furthermore, the current analysis focused only on the calculation of sensible loads, therefore relative humidity and latent loads were not considered in the present study.

\section{Economic analysis and construction times}

An economic analysis was conducted with the aim of assessing the cost effectiveness of the various analysed solutions. Firstly, the cost of construction of the walls for the different alternatives was estimated by referring to regional price lists and market survey (Regional Price List, 2018). Table 7 displays the cost of construction, distinguishing between material costs and labour costs.
Table 7. Construction cost and impact of materials and labour for each technical alternative.

\begin{tabular}{|c|c|c|c|c|c|}
\hline Wall Type & $\begin{array}{c}\text { Total } \\
\text { cost } \\
{\left[€ / \mathbf{m}^{2}\right]} \\
\end{array}$ & $\begin{array}{c}\text { Materials } \\
\text { cost } \\
{\left[€ / \mathbf{m}^{2}\right]} \\
\end{array}$ & $\begin{array}{c}\text { Labour } \\
\text { cost } \\
{\left[€ / \mathbf{m}^{2}\right]}\end{array}$ & $\begin{array}{c}\text { Materials } \\
\text { incidence } \\
{[\%]}\end{array}$ & \begin{tabular}{|c} 
Labour \\
incidence \\
{$[\%]$}
\end{tabular} \\
\hline Brick & 156.54 & 69.60 & 86.94 & 44 & 56 \\
\hline Ref ICF & 136.74 & 75.23 & 61.51 & 55 & 45 \\
\hline ICF mod_1 & 116.77 & 55.06 & 61.71 & 47 & 53 \\
\hline ICF mod_2 & 119.33 & 57.16 & 62.17 & 48 & 52 \\
\hline ICF mod_3 & 125.47 & 62.20 & 63.28 & 50 & 50 \\
\hline ICF mod_4 & 112.42 & 51.50 & 60.93 & 46 & 54 \\
\hline ICF mod_5 & 130.45 & 66.28 & 64.17 & 51 & 49 \\
\hline
\end{tabular}

The standard ICF system saves about $13 \%$ of the total construction cost compared to the traditional brick wall. This saving is attributable to the lower labour cost of ICF system as it permits a faster construction than masonry. In fact, in spite of the increase in material costs of $7.5 \%$, the Ref ICF wall allows a saving on labour of almost $30 \%$ compared to the Brick wall. The construction time estimated based on the percentage of labour costs is, in fact, of $3.00 \mathrm{~h} / \mathrm{m}^{2}$ for the brick wall while an execution time of $2.12 \mathrm{~h} / \mathrm{m}^{2}$ is required for the ICF wall. Therefore, the reference ICF wall has a lower initial cost than the brick masonry wall. However, with regard to energy consumption, the Ref ICF wall determines a slightly higher annual cooling energy than the traditional masonry wall. In order to assess the cost-effectiveness of these first two solutions, discounted cash flows were calculated, considering a discount rate $(d)$ of $4 \%$, an average electricity cost of $0.25 € / \mathrm{kWh}$, and an inflation rate $(e)$ of $3 \%$. Starting from the initial extra-cost generated by the brick construction, the discounted annual savings have been subtracted. The net present value over a period of 30 years is negative. This means that the higher initial cost incurred to realize the brick construction, that consumes less annual cooling electricity than the Ref ICF wall, is not repaid by the lower running costs of the building in 30 years. The annual saving achievable is, in fact, very low and does not allow to payback the investment in the time considered. Therefore, the Ref ICF wall is more costeffective than Brick wall. A very high inflation rate of energy costs (i.e. $10 \%$ ) would lead to repay the extra-cost in 26 years. The two scenarios are illustrated in figure 6 . Concerning the modified ICF solutions, these imply an initial expense lower than both the Brick wall and Ref ICF wall. The saving is, in this case, mainly due to the lower cost of the used materials, which are cheaper than the insulating material used in the Ref ICF wall. Furthermore, all the modified ICF walls, expect the ICF mod_2 alternative, involve an annual energy consumption lower than both the Brick and the Ref ICF walls. At this starting benefit, the annual savings due to the lower energy cost spent to cool the building can be added. In order to identify the most economically viable solution among the five proposed ICF alternatives, the initial savings and the discounted annual saving are outlined in figures 7 and 8 , reporting the savings of the modified ICF walls, with respect to the brick wall and to the reference ICF wall, respectively. 


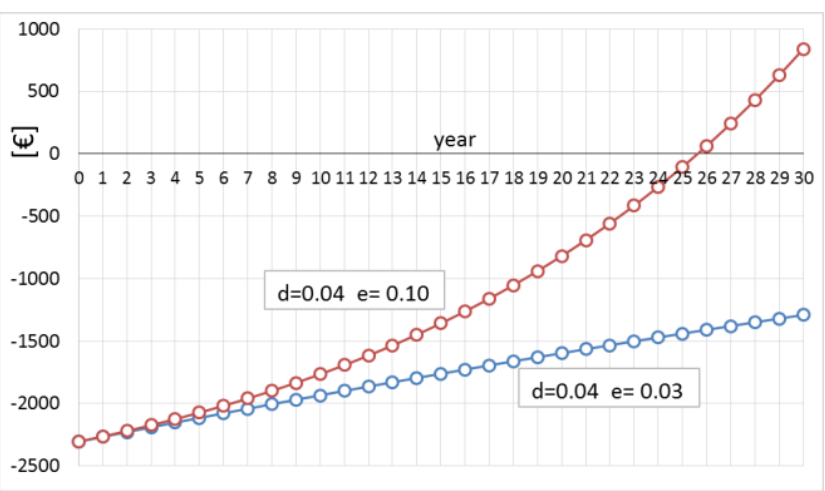

Figure 6. NPV trend of the difference in costs between the Brick wall and the Ref ICF wall over a 30-year period and upon variation of the inflation rate. 6000

2000 0-0-0-0-0-0-0-0-0-0-0-0-0-0-0-0-0-0-0-0-0-0-0-0-0-0-0-0-0-0-0

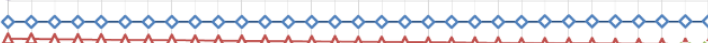
$4000 \Delta-\Delta-\Delta-\Delta-\Delta-\Delta-\Delta-\Delta-\Delta-\Delta-\Delta-\Delta-\Delta-\Delta-\Delta-\Delta-\Delta-\Delta-\Delta-\vec{x}-\hat{x}=\hat{x}-\hat{x}=\hat{x}=\hat{x}=\hat{x}=\vec{x}$

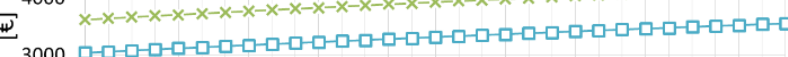
2000

1000

$0 \longdiv { 0 1 2 3 4 5 6 7 8 9 1 0 1 1 1 2 1 3 1 4 1 5 1 6 1 7 1 8 1 9 2 0 2 1 2 2 2 3 2 4 2 5 2 6 2 7 2 8 2 9 3 0 }$ year

$\checkmark$-Brick - ICF mod_1 $-\triangle$-Brick - ICF mod_2 -x-Brick - ICF mod_3

-O-Brick - ICF mod_4 - 4 -Brick - ICF mod_5

Figure 7. NPV trend of the difference in costs between the modified ICF walls and the Brick wall over a 30 year period $(d=0.04, e=0.03)$

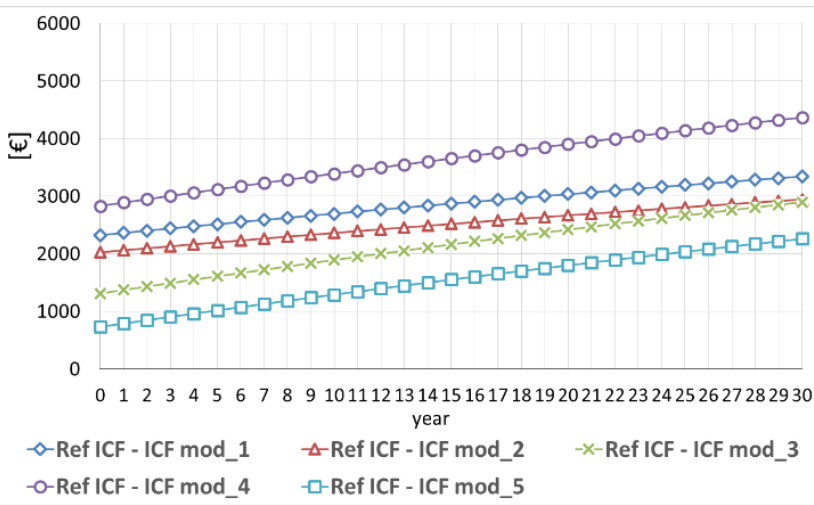

Figure 8. NPV trend of the difference in costs between the modified ICF walls and the Reference ICF wall over a 30-year period $(d=0.04, e=0.03)$

As shown in figure 7 , the modified ICF walls guarantee a saving on the initial cost that varies from $3038 €$ (ICF mod_5) and $5037 €$ (ICF mod_4). The ICF mod 2 solution presents an initial gain of $4333 €$, but this beginning advantage is partly depleted by the increased annual energy consumption with respect to the brick masonry building. The ICF mod_1 solution has an initial gain of $4631 €$, but the annual consumption is approximately equal to the Brick wall, so no significant additional annual earnings during the 30 years are registered. Among the remaining four modified ICF alternatives, the most cost-effective one is the ICF mod_4 which allows for a total saving of $5658 €$ over 30 years.
Regarding the comparison between the modified ICF solutions with respect to the Ref ICF wall (Figure 8), all the proposed alternatives offer savings compared to the Ref ICF wall, both on the initial construction cost and on operating cost. In particular, savings on initial cost range between $732 €$ (ICF mod_5) and $2832 €$ (ICF mod_4). Considering a 30 -year period, the most advantageous solution is the ICF mod_4 which saves $4367 €$ over the analysed period.

\section{Conclusions}

The study analysed the performance of upgraded ICF constructions modified in order to be adapted to a warm climate, such as the Mediterranean. A potential improvement consisting in the replacement of the insulating internal formwork with a layer made of material with a higher thermal conductivity has proved to be successful. This solution, in fact, allows to keep all the advantages offered by the ICF technique (flexibility, seismic safety, rapid construction, waterproofing, thermal and acoustic insulation, limitation of thermal bridges, ease of technical system integration). And, in addition, it increases the thermal inertia of the envelope, allowing to better exploit the thermal storage capacity of the concrete mass inside the wall, which otherwise remains unused as it is shielded by the thermal insulation layer. Various alternative materials were considered in order to replace the internal formwork, resulting in an improved behaviour with respect both to a traditional brick wall and to a standard ICF wall. The best energy performance is provided by the material with the highest thermal conductivity (gypsum fibre panel). However, the most cost-effective solution is represented by the plasterboard, which allows considerable savings on the initial construction cost and a reduction of $19.5 \%$ of the annual cooling energy.

\section{References}

Al-Sanea, S.A., Zedan, M.F., Al-Hussain, S.N. (2012). Effect of thermal mass on performance of insulated building walls and the concept of energy savings potential. Applied Energy (89), 430-442.

Amer-Yahia, C., Majidzadeh, T. (2012). Inspection of Insulated Concrete Form walls with Ground Penetrating Radar. Construction and Building Materials (26), 448-458.

Arun Solomon, A., Hemalatha, G. (2017). Inspection of properties of Expanded Polystyrene (EPS), Compressive behaviour, bond and analytical examination of Insulated Concrete Form (ICF) blocks using different densities of EPS. International Journal of Civil Engineering and Technology (8), 209-221.

Arunraj, E., Solomon, A., Hemalatha, G. Compressive Strength of Insulated Compressive Strength of Insulated Concrete Form Blocks. National Conference on Technological Innovations in Structural Engineering. 2014.

Ascione, F., Bianco, N., De Rossi, F., De Masi, R.F., Vanoli, G.P. (2016a). Concept, Design and Energy 
Performance of a Net Zero-Energy Building in Mediterranean Climate. Procedia Engineering (169), 26-37.

Ascione, F., De Masi, R.F., de Rossi, F., Ruggiero, S., Vanoli, G.P. (2016b). Optimization of building envelope design for nZEBs in Mediterranean climate: Performance analysis of residential case study. Applied Energy (183), 938-957.

Bhatti, A.Q. (2016). Application of dynamic analysis and modelling of structural concrete insulated panels (SCIP) for energy efficient buildings in seismic prone areas. Energy and Buildings (128), 164-177.

Bruno, R., Arcuri, N., Carpino, C. (2015). The passive house in Mediterranean area: parametric analysis and dynamic simulation of the thermal behaviour of an innovative prototype. Energy Procedia (82), 533-539.

Causone, F., Pietrobon, M., Pagliano, L., Erba, S. (2017). A high performance home in the Mediterranean climate: From the design principle to actual measurements. Energy Procedia (140), 67-79.

D. M. 26 Giugno 2015 “Applicazione delle metodologie di calcolo delle prestazioni energetiche e definizione delle prescrizioni e dei requisiti minimi degli edifici". Gazzetta Ufficiale del 15-07-2015.

D.P.R. 412/93 "Regolamento recante la progettazione, l'installazione, l'esercizio e la manutenzione degli impianti termici degli edifici ai fini del contenimento dei consumi di energia, in attuazione dell'art. 4, comma 4, della L. 9 gennaio 1991, n. 10", Gazzetta Ufficiale del 14-10-1993.

DesignBuilder Software Ltd, DesignBuilder Version 4.6.0.015, (2016).

Directive 2010/31/EU of the European Parliament and of the Council of 19 May 2010 on the energy performance of buildings (recast). Official Journal of the European Union 2010. 18/06/2010.

EnergyPlus Version 8.4.0, (2015). U.S. Department of Energy, available at https://energyplus.net/, accessed on 18 January 2019

Ekrami, N., Garat, A., Fung, A.S. (2015a). Thermal Analysis of Insulated Concrete Form (ICF) Walls. Energy Procedia (75), 2150-2156.

Ekrami, N., Kamel, R.S., Garat, A., Amirirad, A., Fung, A.S. (2015b). Applications of active hollow core slabs and insulated concrete foam walls as thermal storage in cold climate residential buildings. Energy Procedia (78), 459-464.

Fadejev, J., Simson, R., Kurnitski, J., Bomberg, M., (2017). Thermal mass and energy recovery utilization for peak load reduction. Energy Procedia (132), 3944.

Harkouss, F., Fardoun, F., Biwole, P.H. (2018). Passive design optimization of low energy buildings in different climates. Energy (165), 591-613.
Kosny, J., Childs, P., Petrie, T., Gawin, D., Desjarlais, A., Christian, J. Energy benefits of application of massive walls in residential buildings. (2001). Report of Oak Ridge National Laboratory, US Department of Energy.

Lizana, J., Chacartegui, R., Barrios-Padura, A., Valverde, J.M. (2017). Advances in thermal energy storage materials and their applications towards zero energy buildings: A critical review. Applied Energy (203), 219-239.

Maref, W., Armstrong, M., Saber, H., Rousseau, M., Ganapathy, G., Nicholls, M., Swinton, M. C. Field energy performance of an insulating concrete form (ICF) wall.(2012). Report of National Research Council Canada. Institute for Research in Construction.

Meteonorm (2017). Meteonorm Global Meteorogical Database Version 7.1.8.

Němeček, M., Kalousek, M. (2015). Influence of thermal storage mass on summer thermal stability in a passive wooden house in the Czech Republic. Energy and Buildings (107), 68-75.

Regional Price List, available at http://www.regione.abruzzo.it/osservatorioappalti/pre zzario/ accessed on 12 December 2018

Rodriguez-Ubinas, E., Montero, C., Porteros, M., Vega, S., Navarro, I., Castillo-Cagigal, M., Matallanas, E., Gutiérrez, A. (2014). Passive design strategies and performance of Net Energy Plus Houses. Energy and Buildings (83), 10-22.

Schnieders, J., Feist, W., Rongen, L. (2015). Passive Houses for different climate zones. Energy and Buildings (105), 71-87.

Selvapandian A., Ramachandran K.P., Neeraja. (2014). Feasibility of using insulated concrete forms in hot and humid climate. International Journal of Civil Engineering and Technology (5), 66-72.

Shafigh, P., Asadi, I., Mahyuddin, N.B. (2018). Concrete as a thermal mass material for building applications A review. Journal of Building Engineering (19), 1425.

Siddiqui, O., Kumar, R., Fung, A.S., Zhang, D., White, M.A., Whitman, C.A. (2017). Modelling for performance prediction of highly insulated buildings with different types of thermal mass. Applied Thermal Engineering (122), 139-147.

Italian Standardisation Organisation. UNI 10349 - 2016. Riscaldamento e raffrescamento degli edifici - Dati climatici - Parte 3: Differenze di temperatura cumulate (gradi giorno) ed altri indici sintetici. 2016.

Italian Standardisation Organisation. UNI/TS 11300-1. Building energy performance - Part 1: Evaluation of the energy need for space heating and cooling (in Italian). 2014. 